Check for updates

Cite this: RSC Adv., 2017, 7, 32246

\title{
A review of nanomaterials for nanofluid enhanced oil recovery
}

\author{
Baoliang Peng, $(D) \dagger^{\star a b}$ Lecheng Zhang, $\uparrow^{\text {cd }}$ Jianhui Luo, ${ }^{\text {ab }}$ Pingmei Wang, ${ }^{\text {ab }}$ Bin Ding, ${ }^{\text {ab }}$ \\ Minxiang Zeng ${ }^{(D)}{ }^{c}$ and Zhengdong Cheng $\left(\mathbb{D}{ }^{* c d e f}\right.$
}

Received 17th May 2017

Applying nanomaterials in nanoflooding is an emerging research topic in nanomaterials and petroleum engineering research. In this review, we analyzed the functions of nanomaterials during nanofluid flooding operations. We summarized different nanomaterials that have been reported to be used for nanofluid flooding in the lab. We concluded different factors that can control nanofluid flooding qualities. Lastly, we discussed the challenges and opportunities present in nanofluid flooding research.

think a technical review on technology innovations, like nanoflooding, would help both academia and upstream industry to grasp the trending of nanoflooding clearly. Compared with conventional chemical flooding, nanofluid flooding has several advantages. By modifying material surface functionalization or altering template materials, engineered nanomaterials can possess additional functions, such as magnetic-responsive and $\mathrm{pH}^{-}$ responsive properties. In addition, the unique functions of nanomaterials allow nanofluid to recover those inaccessible oil reserves using conventional methods. Finally, different from molecular surfactant or polymer stabilized emulsions, nanoparticlestabilized emulsions, also known as Pickering emulsions, are very stable even under harsh reservoir conditions, owing to the well-organized particle layer at the emulsion interface.

Some previous reviews have summarized applications of nanotechnology in enhanced oil recovery from the petroleum engineering perspective. ${ }^{1,5,6,9}$ Shamsi Jazeyi et al. also gave a thorough discussion on application of polymer-coated nanoparticles in enhanced oil recovery. ${ }^{10}$ In this review, we will discuss nanoflooding techniques from the material and colloidal science perspective, focus on the fundamental mechanisms underlying the nanofluid enhanced oil recovery and parameters controlling the success of a nanoflooding operation. Potential functions of nanomaterials in nanofloodings proposed by researchers will be reviewed first to explain two questions: what are the advantages and limitations of nanofluid flooding techniques and what is the potential mechanism of nanofluid flooding. Then, we will summarize current nanomaterials, which have been tested for nanoflooding EOR. Discussion will be based on three categories of material dimensions: zero-dimensional nanostructures (nanoparticles and heteroepitaxial core-shell structures), one-dimensional nanostructures (nanorods, nanowires, and nanotubules), and two-dimensional structure (thin plates, sheets). We will also summarize data to help readers to compare performance of nanofloodings with different materials under each category. 
Next, we will outline factors that can affect nanoflooding quality, such as particle morphology, surface decoration, and particle environment resistance, to help readers understand how to enhance oil recovery by nanofluids and how to mitigate risks associated with nanofluid floodings. With the advantages of small size and different geometries, different dimensions of nanoparticles can achieve free movement in suitable oil reservoirs of different permeabilities. However, particle morphology and surface decoration of nanomaterials not only affect particle retention in the formation but also change emulsion stability. Different knowledges on the nanomaterial structures and morphologies, surface decorations and emulsion stabilizations can help engineers and scientists to implement nanofloodings in a more successful way. Finally, we will discuss the potential opportunities and challenges of nanomaterial-assisted EOR.

\section{Functions of nanomaterials in nanofloodings}

\section{Wettability alteration}

Wettability alteration is a well-known practice for oil-wet and mix-wet formation enhanced oil recovery. ${ }^{11,12}$ Formation surface contacted and reacted with underground oil reserve for millions of years before recovery processes were developed, so reservoirs normally show oil-wet or mix-wet formations. By changing formation wettability, capillary force will decrease and mobility of the oil phase will be enhanced. The general mechanism of wettability alteration has been well studied and reported by different literatures. ${ }^{\text {13-15 }}$ The common explanation is either surfactant absorbing on rock surfaces altering wettability or natural lyophilic surfactant generated by crude oil oxidization removed by ion pairs. For nanofloodings, wettability alteration mechanism is slightly different as reported. Karimi et al. ${ }^{\mathbf{1 1}}$ observed wettability alteration in carbonates surface with zirconium oxide nanofluid (shown in Fig. 1). With microscopic

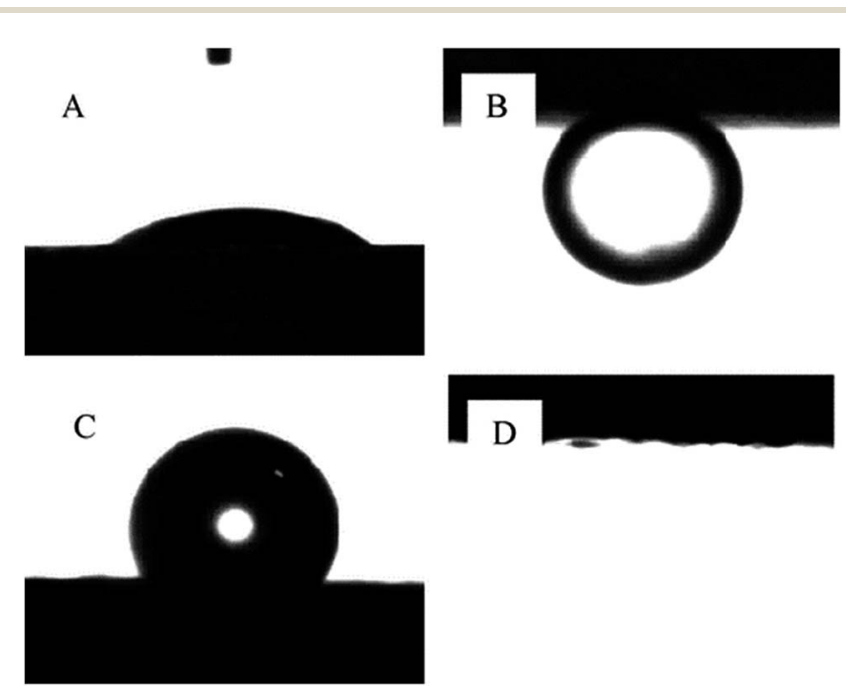

Fig. 1 Wetting conditions for rock surface in different phases ((A) air/ water, (B) water/n-heptane) and a carbonate rock aged in the oil ((C) air/water, (D) water/n-heptane). (Reprinted with permission from (ref. 11). Copyright (2012) American Chemical Society.) imaging and theoretical calculation, authors propose the wettability alteration is due to $\mathrm{ZrO}_{2}$ deposition on the rock surface and governed by the partition coefficient of nanomaterial in water and oil phases. Their result also shows the wettability alteration by nanofluid is a slow process that may take days to finish. Other researchers proposed to use surfacemodified material for wettability alteration. Recently, Luo et al. ${ }^{\mathbf{1 6}}$ reported "climbing film", which is an assembly of surface-modified Janus graphene nanosheets that serve to reverse wettability of solid surfaces, shown in Fig. 2. The same wettability alterations by nanoparticles and the nanoparticle mixture were also reported by Giraldo et al. ${ }^{17}$ Maghzi et al. ${ }^{18}$ and Dehghan Monfared et al. ${ }^{12}$ According to above literatures, wettability alteration can be affected by particle size, cosurfactants, $\mathrm{pH}$ value and ion strength. ${ }^{10}$ We have also noticed that some researchers claimed $\mathrm{SiO}_{2}$ nanoparticles can also be applied as an augmented injection agent. However, the mechanism for depression and augmented injection is very similar to the wettability alteration..$^{19,20}$

\section{Reduction of interfacial tension}

To increase oil recovery ratio, one of the common strategies is to reduce the oil-water interfacial tension. For conventional chemical flooding, interfacial tension is a standard parameter to be used for surfactant characterization. The lowest oil-water interfacial tension by molecular surfactant can reach $10^{-3}$ to $10^{-2} \mathrm{mN} / \mathrm{m} .^{21,22}$ Although nanofluid systems cannot achieve that small interfacial values, researchers try to reduce interfacial tension between oil and water by nanomaterials. ${ }^{23-25}$ The most common method is thorough surface-modification or asymmetrical surface-modification. If nanoparticles or nanoplatelets are modified with hydrophobic and hydrophilic groups on opposite sides, creating a Janus particle (named by Nobel Laureate P. G. de Gennes ${ }^{26}$ ), then the particle has the potential to reduce interfacial tension (IFT) sharply. The surface activity of Janus particle is dependent on its surface modifications. To use Janus particles as active surfactants, each side of the particle
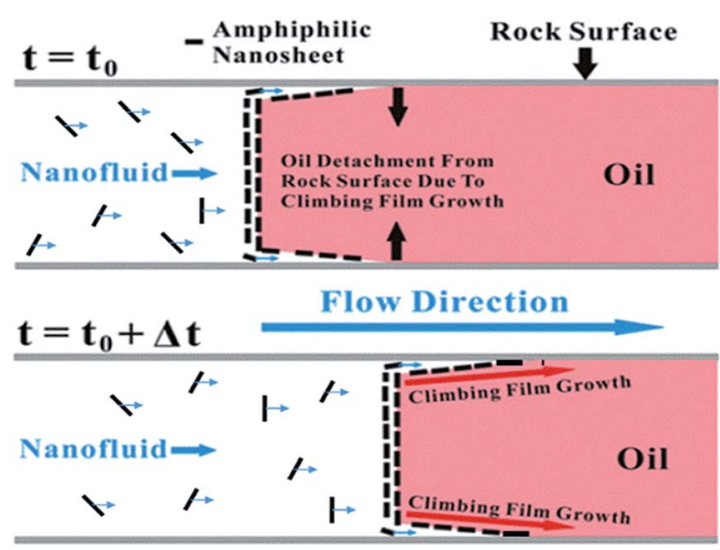

Fig. 2 Oil displacement mechanism proposed by Luo et al. (Figure adapted from (ref. 15). Reprint permission is waived by PNAS for educational use.) 
must exhibit distinctive surface hydrophilicity. ${ }^{27}$ More detail will be discussed in the surface modification section later.

\section{Controllable viscosity}

Another important dimensionless number in EOR is mobility ratio, which is the ratio between the displacing fluid and displaced fluid. A higher mobility ratio is desired for more oil displacement, under which has a higher sweep efficiency and less fingering effect in the reserve. ${ }^{21}$ Nanofluids have been reported to be used to reduce oil viscosity and increase displacing fluid viscosity. Both factors will contribute to increase mobility ratio and as a result, boost oil recovery ratio. ${ }^{28}$

\section{Disjoint pressure for oil displacement}

A disjoining pressure at the oil-water-solid contact region has been observed and studied during nanoflooding, which is one of the driving forces to expel oil from rock surface..$^{29,30}$ The pressure magnitude is related with wedge film thickness and nanoparticle structure and can be theoretically calculated (Fig. 3). ${ }^{31}$ Recently Zhang et al. ${ }^{32}$ displayed their work on crude oil displacement with nanofluid. They concluded that disjoining pressure is the mechanism underlying their successful oil displacement with sandstone experiment.

\section{Stable foam and emulsion under harsh conditions}

Harsh conditions, i.e. high temperature, high pressure and high salinity, are always challenges for conventional molecular surfactant flooding because under harsh conditions, molecular surfactant may undergo phase separation and render the surfactant solution into inhomogeneous phases. ${ }^{33}$ Nanoparticles and surface-modified nanoparticles, on the other hand, have been reported with high thermal stability and been analyzed with flooding experiment in laboratory. ${ }^{34,35}$ Moreover, foam stability and emulsion stabilization are important for conducting flooding for reservoirs with harsh conditions. Pickering emulsion and Pickering foam have shown stability under

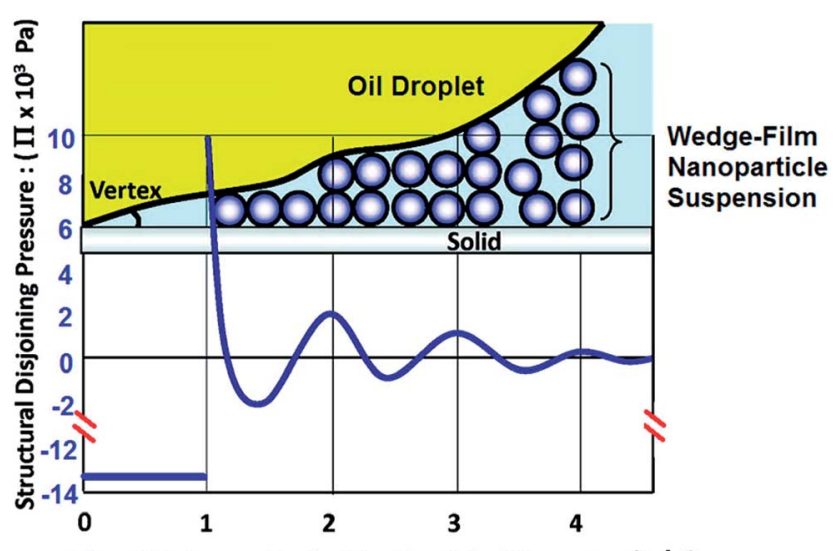

Film Thickness Scaled by Particle Diameter (h/d)

Fig. 3 Schematic shows nanoparticle wedge film confined by solid surface and oil-nanofluid interface and relationship between disjoining pressure and film thickness. (Reprinted with permission from (ref. 32). Copyright (2014) American Chemical Society.) extreme conditions..$^{36,37}$ Thermal stability would be another merit that nanoparticles can contribute to the flooding procedure. Stabilization of Pickering emulsions can be controlled by manipulating particle morphology and surface modification. Synthesis of anisotropic particles have been reported previously. ${ }^{38-40}$ Stable foam or emulsion is necessary for emulsion or foam flooding. From the perspective of thermal dynamics, reserved oil bank will tend to become emulsified and mobilized if the emulsified oil can form stable emulsions, thereby increasing oil recovery ratio. A major application of surface modified nanoparticles, therefore, is stabilization of emulsions and foams. ${ }^{41}$ Zhang et al. applied silica nanospheres that have been surface-modified with PEG on foams and emulsions to promote conformance. ${ }^{37,42}$ Meanwhile, hydrophobic silica particles stabilized water $/ \mathrm{CO}_{2}$ emulsion was firstly reported by Adkins et al. ${ }^{43}$ Emulsion ripening and coalescence is not obvious, however, the author concluded that particle sedimentation is the major contribution for destabilization. Later, Janus particles are reported to be used for $\mathrm{CO}_{2}$ flooding, a popular technique for EOR in areas where $\mathrm{CO}_{2}$ can be easily achieved. ${ }^{44,45}$ Guo et al. studied silica and clay stabilized $\mathrm{CO}_{2}$ foam structure and its EOR applications. They demonstrated that $\mathrm{CO}_{2}$ foam is improved by the nanoparticle and surfactant mixture. ${ }^{46}$

\section{Nanomaterials for nanoflooding}

\section{Zero-dimensional nanomaterials}

In this section, we will review several laboratory experiments investigating the use of zero-dimensional nanoparticles for oil recovery and oil recovery ratio with zero-dimensional nanoparticles. Silica dioxide, among other zero-dimensional materials, has been used to increase oil recovery ratio. To study oil sweep efficiency of silica particles under different conditions, Skauge et $a l^{47}$ conducted experiments on hydrophilic silica nanoparticles and compared the result with polystyrene nanoparticles. Results show that silica particles possess a low differential pressure and small permeability reduction. With further investigation, Skauge found when system combined with brine or with a $300 \mathrm{ppm}$ polymer solution, there is no significant oil mobilization; however, if applied with a $600 \mathrm{ppm}$ polymer solution which has a higher viscosity, the oil bank can be mobilized. The author hypothesizes that this result is due to silica particles being "log-jammed" at the pore throat, thus requiring a high viscosity to generate the oil bank during microscopic observation. Hendraningrat et al. also studied zerodimensional nanoparticles sweep efficiency with glass microchannels and microchips (shown in Fig. 4). He found that 0.1 wt\% silica particles flooding can achieve higher oil recovery ratio compared to the brine control group. ${ }^{48}$ Researchers have also tried other zero-dimensional nanoparticles than silica for enhanced oil recovery. Ogolo $e t$ al. $^{28}$ tested nanoparticles other than silicon dioxide, such as aluminum oxide and magnesium oxide, with different solvents. In these trials, aluminum oxide with distilled water achieved the most successful flooding result. This solution delivered $12.5 \%$ more on oil recovery ratio than slick water flooding. 

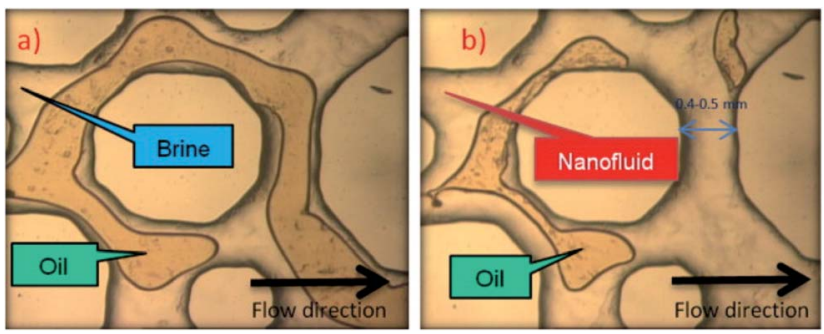

Fig. 4 Flooding experiment carried out with microfluidic chip (a) brine flooding (b) silica particle nanoflooding. Hendraningrat et al. concluded that nanofluid can potentially increase recovery rate. (Reprinted with permission from (ref. 48). Copyright (2013) Elsevier.)

Another category of zero-dimension material used in the oil field is nanocapsulates. The encapsulated breaker has already been used in hydraulic fracturing to reduce the viscosity of cross-linked systems. ${ }^{49}$ Some researchers also proposed to use encapsulated self-healing polymers for storage tank and pipeline self-repair. ${ }^{50}$ The use of nanoencapsulation for enhanced oil recovery have been proposed in Bennetzen's paper. ${ }^{51}$ In the paper, Bennetzen mentioned that fluorescent encapsulate can be used as a tracer to differentiate different reservoir conditions, such as $\mathrm{pH}$ value, temperature, oil water content and salinity. Also, nanoencapsulates can be used to deliver chemicals to specific regions then triggered to release chemicals.

\section{One-dimensional nanomaterials}

Because of its natural abundance and accessibility, onedimensional nanofibers and nanotubes have been examined for oil recovery and oil emulsification. One of the most popular one-dimensional nanofiber is carbon nanotubes. Several researchers reported that carbon nanotubes demonstrated superoleophilicity and can be applied in oil/water emulsion stabilization. Hu et al. demonstrated, by grafting onedimensional carbon nanotube (CNTs) onto functionalized graphene aerogel surface, the aerogel shows superhydrophobicity and oleophilicity. The capacity and selectivity can also be finetuned by pore size and channel diameter. ${ }^{52}$ Zhai et al. reported silver phosphate and multiwall carbon nanotubestabilized Pickering emulsion for photo catalysis use. ${ }^{53}$ Shen et al. used carbon nanotube/silica nanohybrids to stabilize decalin and showed controllable emulsion type and volume fraction with different particle concentrations. ${ }^{54}$ Applying synthetic amphiphilic nanorods for EOR may increase the cost of production. A more feasible and cost-effective solution is applying natural material. Kusanagi et al. reported core flooding results with cellulose nanofibers. To control fluid mobility, 0.4 $\mathrm{wt} \%$ cellulose nanofiber and crosslinker $\mathrm{AlCl}_{3}$ were injected into an inhomogeneous core sample. The crosslinked cellulose fiber was able to control mobility of nanofluid and increase recovery ratio from $13.3 \%$ to $24.3 \%$; however, severe filtration was also observed during experiment. ${ }^{55}$ Titanium dioxide nanoparticles and nanorods have been used in nanofloodings. Ehtesabi et al. ${ }^{\mathbf{5 6}}$ applied anatase and amorphous titanium dioxide in core flooding test and they found oil recovery ratio increased to $80 \%$ compared to the value for pure water flooding $49 \%$. With further testing, they concluded that the reason of increasing oil recovery ratio is rock wettability change by the nanorods. Some papers reported using low-cost natural one-dimensional material to stabilize emulsions. Kalashnikova et al. reported hexane/ water emulsion stabilized by bacterial cellulose nanocrystals, nanofibers from cotton, and other natural nanofibers. ${ }^{57,58}$ Nanofibers with different aspect ratios were utilized in their experiments. They found aspect ratio could influence emulsion surface coverage of nanofibers.

\section{Two-dimensional nanomaterials}

Variations in particle geometry can greatly change the properties of emulsions, including ability to reduce interfacial tension, emulsion and foam stabilization, ${ }^{59}$ which is essential for emulsion and foam flooding under harsh reservoir conditions. Numerical simulation work justified two-dimensional material is more favored for emulsion stabilization in comparison with zero-dimensional and one-dimensional materials. Creighton et $a{ }^{60}{ }^{60}$ presented a thermodynamic model to analyze the free energy change during particle stabilization, shown in Fig. 5. For two-dimensional thin film, the stabilization energy can be expressed as:

$$
\Delta G=\pi R^{2}\left[\gamma_{\mathrm{o} / \mathrm{w}}-\left|\gamma_{\mathrm{o} / \mathrm{s}}-\gamma_{\mathrm{w} / \mathrm{s}}\right|\right]
$$

where $R$ is radius of disk, $\gamma_{\mathrm{o} / \mathrm{w}}$ is oil/water interfacial tension, $\gamma_{\mathrm{o}}$ / s is oil/disk interfacial tension, and $\gamma_{\mathrm{w} / \mathrm{s}}$ is water/disk interfacial tension. Creighton et al. further developed the equation by applying Young's equation. They found that the Gibbs energy change is related to emulsion droplet radius, interfacial tension, and three-phase contact angle. Many types of twodimensional nanomaterials have been used to prepare emulsions. Graphene and graphene oxide are common carbon-based nanosheets. Kim et al. ${ }^{\mathbf{6 1}}$ reported amphiphilic graphene oxide sheet in 2010, shown in Fig. 6. The amphiphilicity is due to the carboxylic group on the edge and to the hydrophobic basal

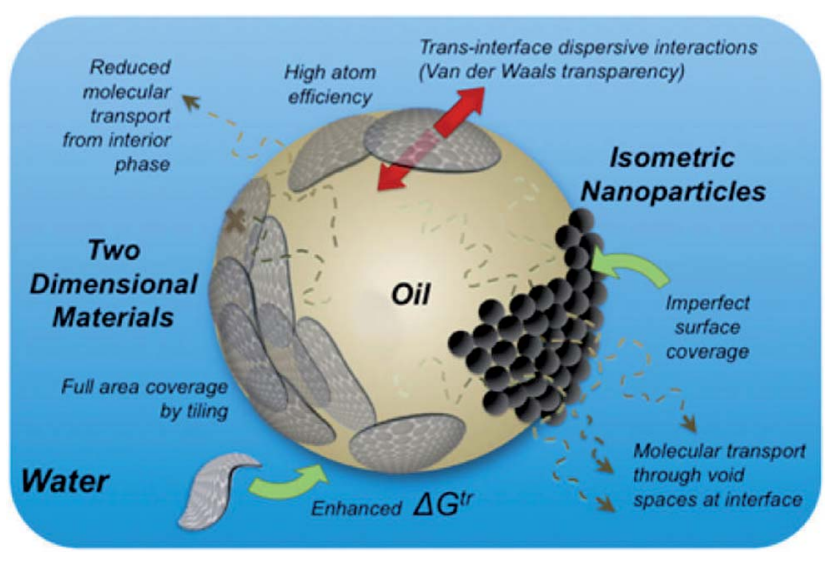

Fig. 5 Schematic illustrates advantage of two-dimensional nanosheets over zero-dimensional nanoparticles to stabilize emulsions. (Reprinted with permission from (ref. 60). Copyright (2014) American Chemical Society.) 
Air-Water

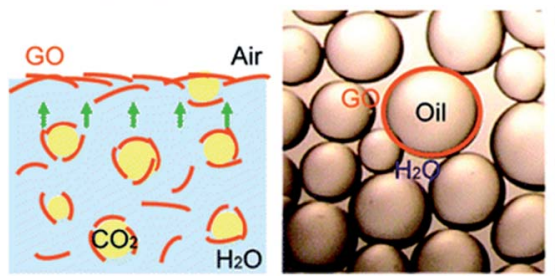

Liquid-Solid

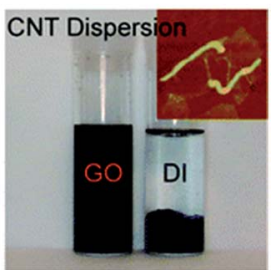

Fig. 6 Amphiphilic graphene oxide between different interfaces (Reprinted with permission from (ref. 61). Copyright (2010) American Chemical Society.)
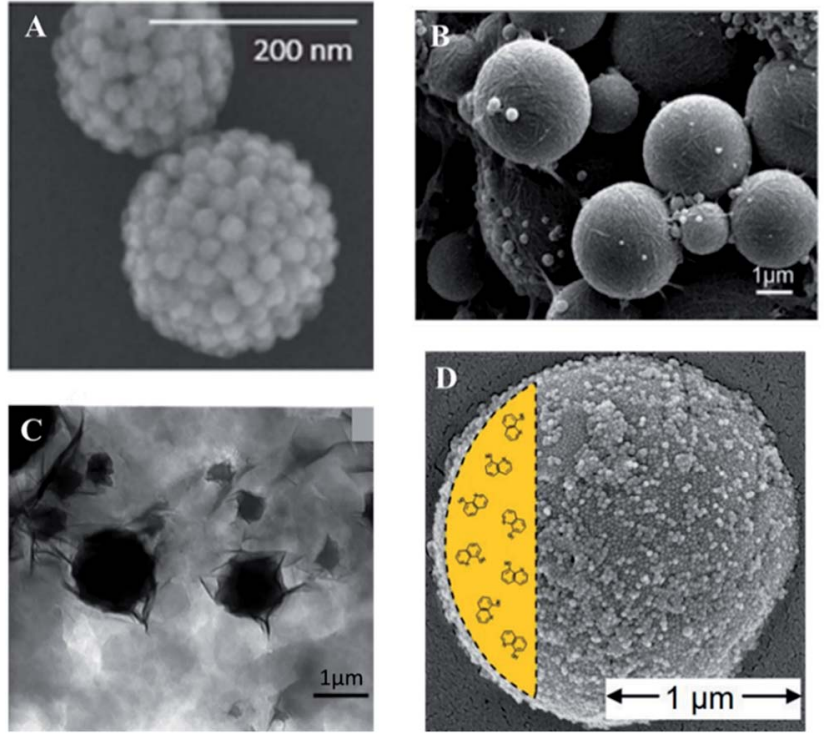

Fig. 7 (A) Hydrophilic silica nanoparticles stabilized by inverse Pickering emulsion droplets (reprinted with permission from, (ref. 69) copyright (2015) American Chemical Society). (B) Polystyrene stabilized by bacteria cellulose nanofibers reported by Kalashnikova et al. (reprinted with permission from (ref. 57). Copyright (2011) American Chemical Society). (C) Polyacrylamide (PAAm) latex particles stabilized by surface modified montmorillonite. (adapted with permission from (ref. 70). Copyright (2006) American Chemical Society). (D) $\mathrm{pH}$ sensitive encapsulates stabilized by silica particles reported by Haase et al. (reprinted with permission from (ref. 68). Copyright (2010) American Chemical Society).

surface. By changing $\mathrm{pH}$ value, dissociation of carboxylic varies, resulting a tunable amphiphilicity. Luo et al. ${ }^{16}$ successfully modified a single face of graphene oxide and reported a $15.2 \%$ increase in oil recovery ratio. By applying modified graphene at the interface of oil and water, they generated an interfacial film with strong elasticity that exhibits special properties of a twodimensional material.

Other two-dimensional materials, especially low-cost natural clay disk materials, have also been modified and used as emulsifiers and foam stabilizers. Mejia et al. ${ }^{62}$ modified zirconium phosphate surface with octadecyl isocyanate, then exfoliated the zirconium phosphate structure to generate Janus and Gemini platelets. They also found that emulsion droplet size is related to particle concentration. Based on the modification method published by Mejia, ${ }^{62} \mathrm{Yu}$ et al. varied surface functionalization groups. Using the $0.4 \mathrm{wt} \%$ modified zirconium phosphate nanoplatelet, they achieved a high oil recovery ratio. In the same work, they also demonstrated synergetic effect between zirconium phosphate and molecular alkyl polyglycoside (APG) surfactant on enhanced oil recovery. ${ }^{63}$ Later, Wang et al. ${ }^{64}$ used the Janus surfactant developed in Mejia's paper to encapsulate phase changing material (PCM), which is thermally stable and uniform in particle size. The successful application of Janus particle surfactant verified the functionality of Janus nanoplatelets for oil emulsification. Guillot et al. studied LAPONITE® and montmorillonite behavior at the water/oil interface. ${ }^{65}$ According to their publication, in some trials, although the montmorillonite plate sizes are larger than emulsion droplets, the plates wrap around the emulsion droplets to stabilize them. Yang et al. found paraffin/water emulsion can be solely stabilized by layered double hydroxide. They proposed the mechanism of stabilization is due to reduction of zeta potential. ${ }^{66}$ Fig. 7 shows oil phases stabilized by different dimensions of nanomaterials. Table 1 summarizes materials used for nanoflooding by different dimensions that are discussed in this paper.

\section{Factors controlling success of nanoflooding}

Examining results obtained from laboratories, it appears that nanofloodings techniques have advantages over conventional flooding techniques for oil emulsification, wettability alteration and foam stabilization, and they possess unique mechanisms for oil displacement. ${ }^{6,12,17,27}$ Before practical application, however, nanomaterials must be assessed to determine if they satisfy a criterion to carry out an enhanced oil recovery operation successfully without causing damage to the reservoir. Following are several factors that can affect nanoflooding quality:

Table 1 Some examples of material that can be potentially used in nanoflooding for EOR

\begin{tabular}{lll}
\hline Dimension & Material & Research examples \\
\hline Zero-dimensional & $\begin{array}{l}\text { Silica; surface-modified silica; silica hybrids; } \\
\text { silica dumbbell; aluminum oxide; magnesium } \\
\text { oxide; }\end{array}$ & Ref. 28, 41, 47, 67 and 68 \\
Cne-dimensional & narbon nanotubes; bacterial cellulose & Ref. 53-55, 57 and 58 \\
Two-dimensional & Graphene; graphene oxide; clay materials & Ref. 16, 61 and 62
\end{tabular}




\section{Nanomaterial structure}

A major concern of applying nanoparticles in EOR is material swelling causing formation jamming and formation damage ${ }^{71}$ especially for unmodified clay nanomaterials with layered structures which can be intercalated with formation water. After interacting with water, exchangeable ions within the clay structure will hydrate and expand the $d$-space of layered clay material. A $60 \%$ to $380 \%$ increase in $d$-space has been observed, which is the root cause for severe formation damage. ${ }^{72}$ Applying swelling inhibitors (like $\mathrm{K}^{+}$) or using exfoliated clay materials ${ }^{72-74}$ can mitigate material swelling issues and thus solve the formation damage problem. Gonzalez et al. reported applying swelling inhibitors can achieve a swelling reduction up to $60 \% .{ }^{75}$ Exfoliation and delamination of different lamellar clay materials have also been well studied in laboratory. ${ }^{76-78}$

\section{Nanomaterial morphology}

Physical size of the pore throat will place a physical limitation on the success of nanoparticle-assisted EOR, thus right morphology is an important criteria for successful nanoflooding operation. If the particle size is larger than the pore throat, then materials cannot propagate through the pore neck, and formation damage is inevitable. In some cases, although the size of individual particles is smaller than pore throat size, the materials still cannot pass through the pore neck due to the log-jamming phenomenon. ${ }^{6}$ Particle retention and entrapment are the main causes of log jamming. ${ }^{48,79}$ To prevent potential formation damage, particle size has to be controlled to let material pass through the throat neck freely. Meanwhile, particle hydrophobicity, fluid ion strength, and formation conditions should also be considered and modified to avoid jamming. The ratio of particle size to pore size and fluid velocity are two other factors controlling retention and entrapment. ${ }^{\mathbf{8 0}}$ Different papers have discussed nanoparticle entrapment theoretically and experimentally. ${ }^{\mathbf{8 1 , 8 2}}$ According to the analysis in the above papers, particle retention, therefore, is related to particle morphology and physical size.

Nanoparticle shape and morphology can also play an important role in oil emulsification, as evidenced by interests in particle-stabilized emulsions, also known as Pickering emulsions. ${ }^{83}$ Interface stability is related to surface wettability, aspect ratio, and especially to particle shape. De Folter et al. reported Pickering emulsions with cubic and peanut-shaped particles achieved 90\% surface coverage, higher than that achieved with normal spherical particles. ${ }^{\mathbf{8 4}}$ Gao et al. numerically studied surface activity of different shapes of Janus particles and found sphere and rod shapes have only one equilibrium state, but discotic shapes have another metastable state: reverse orientation. ${ }^{59}$ Madivala et al. observed a strong correlation between particle aspect ratio and emulsion stability. ${ }^{85}$

\section{Formation salinity, temperature and $\mathrm{pH}$ value}

Formation salinity, temperature, and $\mathrm{pH}$ value can impact nanoflooding performance, and inorganic material stability can be affected by those variables. Before implementation, compatibility of nanomaterials with formation conditions, such as formation salinity, temperature and $\mathrm{pH}$ value. McElfresh's recent research examined the influence of temperature and salinity on nanoparticle stability and reported several historical cases of applying nanoparticle dispersions with acid for asphaltene remediation. ${ }^{8}$ Influence of those factors on the organic compounds grafted on the inorganic templates can be more complicated. Apropos of amphiphilicity, different surfactants have different optimal salinities and $\mathrm{pH}$ values, at which interfacial tension will reach its minimum value. The optimal salinity and $\mathrm{pH}$ value are normally measured by an IFT screening test. ${ }^{86}$ Low IFT value will increase oil recovery ratio dramatically. ${ }^{87,88}$ In addition to salinity and $\mathrm{pH}$ value, the relationship between temperature and interfacial tension has also been studied for molecular surfactant systems. ${ }^{89}$ It has been reported that due to effects of chemical stability and electric interaction, high salinity and high temperature will degrade or destabilize molecular surfactant, which is also expected to happen for the surface modifications on the nanomaterials. ${ }^{90} \mathrm{~A}$ thorough surface chemistry compatibility check is suggested.

\section{Surface modification of nanomaterial}

Particle surface chemistry determines particle retention, wettability alteration, ability to emulsify and stabilize emulsions or foams. The intrinsic surface property is decided by pristine material properties; however, with proper surface modification, material surface properties can be controlled. Well-designed surface modifications can change particle hydrophobicity, and thus alleviate particle retention on the rock surface. A lower particle retention is desired, as particle retention is one of the direct causes for formation damage. Rodriguez et al. reported their observations on particle retention of polyethylene glycol (PEG)-coated silica particles. They observed that surface coating naturalizes surface charge on silica particles. As a result, their system has less particle retention compared to other peer research. ${ }^{67}$ Surface charge modification and particle retention are also explained theoretically by Monfared $e t$ al. They studied adsorption of silica nanoparticles on calcite, interpreted obtained data with DLVO theory, and found adsorption follows a second-order model. ${ }^{91}$

Janus particle modification is a special particle surface modification which is very promising to be applied in nanoflooding. In a typical procedure, different functional groups or hydrophobic and hydrophilic polymers will be grafted on the two sides of particles to achieve smaller interfacial tension. Also, nanoparticles with heterogeneous and amphiphilic surface modification are more stable at interface than those with homogeneous surfaces. ${ }^{92}$ Efforts have been made to review the synthesis of Janus particle surfactants, ${ }^{27,93}$ such as the earlier paper reported by Takahara et $a .^{94}$ on Janus silica nanoparticles. Particles were synthesized at the water/oil interface by introducing silane in oil phase. The as-synthesized product is proved to be surface-active by the grafting of gold nanoparticles on the hydroxyl group of silica nanoparticles, and surface tension was quantified with a pendant drop 
measurement. By applying $\mathrm{Au} / \mathrm{Fe}_{3} \mathrm{O}_{4}$ at the hexane-water interface, Glaser et al. ${ }^{23}$ observed a sharp decrease of interfacial tension, and interfacial tension observed on Janus particle systems was observed to be lower than that of non-Janus particles. The same conclusion can be drawn from reports from other researches; for instance, Fernandez-Rodriguez's work on homogeneous and Janus gold nanoparticles. ${ }^{95}$ They reported that surface functionalized Janus particles exhibited better surface activity than homogeneously functionalized gold particles in all testing conditions. As mentioned earlier, reduced interfacial tension can play an important role in displacement of formation residue oil. Moreover, by proper surface modification, emulsification can also be reversibly controlled. ${ }^{68}$ Such precise control of emulsification and deemulsification enables delivery of reagents to desired specific targets in the underground formation.

\section{Intrinsic material properties}

Wisely utilizing intrinsic material properties can facilitate oil recovery procedure. Such intrinsic property could be electrical, ${ }^{96}$ magnetic, ${ }^{97-99}$ rheological $^{\mathbf{1 0 0 , 1 0 1}}$ and thermal ${ }^{\mathbf{1 0 1}}$ properties. Yahya et al. ${ }^{\mathbf{1 0 2}}$ presented their work on cobalt ferrite nanoparticles with electromagnetic waves, which is a very promising method for heavy oil recovery. The magnetic particle would be self-heated under high frequency electromagnetic waves. Then nanoparticles conduct the heat to the surrounded crude oil, reducing the viscosity of crude oil and increasing oil recovery. Ferrofluid is a suspension of paramagnetic materials. Applying ferrofluid for enhanced oil recovery has also been proposed and demonstrated in laboratory. ${ }^{\mathbf{1 0 3}}$

\section{Opportunities and challenges}

Application of nanomaterials in enhanced oil recovery has the potential to improve upstream productivity. Synthesis of different morphologies of nanomaterials is widely studied; its technology had reached a mature state of development. The study of protocols such as core flooding and micro channel chips are well established, although refinement of those tools would still be welcomed. The detail mechanism of nanoflooding, however, is still being studied. More research effort should be addressed toward the study of interaction between nanomaterials and rock surface and oil/water interface. The stability of Pickering emulsions and foam has been proven both theoretically and experimentally, but thus far researchers have rarely applied those knowledge in nanomaterial enhanced oil recovery. At present, the most successful applications of nanomaterials in oil field use are encapsulated breakers and tracers. Successful nanofloodings are only reported in laboratories. We think the immaturity of nanoflooding is due to lack of understanding of the oil displacement mechanism and the behavior of nanoparticle at downhole. The other factors limiting wide application of nanomaterial in oil field use include cost and formation and environment risk assessment.

\section{Conclusions}

In this review, the benefits of nanomaterial enhanced oil recovery is analyzed. The mechanism of nanoflooding could be concluded as wettability alteration, reducing interfacial tension, controllable viscosity, disjoint pressure for oil displacement and a stable foam and emulsion. We also summarized current progress in nanomaterial-assisted EOR based on three categories of material dimensions: zero-dimensional, onedimensional, and two dimensional. We compared oil emulsifiability of the different dimensions. According to simulation results and the thermal dynamic model, two-dimensional material seems to be the optimal candidate to generate stable emulsions. We concluded and assessed the properties of nanomaterials related to successful chemical EOR implementation, such as particle size, morphology, surface decoration and environment resistance, although the requirements for a successful nanoflooding EOR can vary case by case. Some general guidance for nanoflooding EOR is drawn. Nanoparticle size, surface charge and nanomaterial structure should be evaluated before implementation to avoid formation damage and particle retention. Material morphology and surface functionalization should also be controlled to reduce interfacial tension. Material compatibility with formation conditions should also be evaluated before nanoflooding implementation to lower risks. The potential opportunities and challenges of nanomaterial EOR are also discussed. The nanoflooding technique is expected to improve oil displacement efficiency to a large extent, and the research and development of nanomaterial-assisted EOR techniques have the potential to introduce revolutionary changes in the oil industry.

\section{Acknowledgements}

This research project is generously supported by PetroChina Scientific Research and Technology Development Project (2014A-1001; 2014A-1001-01).

\section{Notes and references}

1 A. Fletcher and J. Davis, Presented in part at the SPE Improved Oil Recovery Symposium, Tulsa, Oklahoma, USA, 2010.

$2 \mathrm{X}$. Kong and M. Ohadi, Presented in part at the International petroleum exhibition and conference, Abu Dhabi, UAE, 2010.

3 S. Kapusta, L. Balzano and P. M. Te Riele, Presented in part at the International petroleum technology conference, Bangkok, Thailand, 2011.

4 L. Li, X. Yuan, X. Xu, S. Li and L. Wang, Presented in part at the International petroleum technology conference, Beijing, China, 2013.

5 S. Ayatollahi and M. M. Zerafat, Presented in part at the SPE International oilfield nanotechnology conference and exhibition, Noordwijk, The Netherlands, 2012.

6 A. I. El-Diasty and A. M. Aly, Presented in part at the SPE North Africa technical conference and exhibition, Cairo, Egypt 2015. 
7 J. Sheng, Enhanced oil recovery field case studies, Gulf Professional Publishing, 2013.

8 P. M. McElfresh, D. L. Holcomb and D. Ector, Presented in part at the SPE International Oilfield Nanotechnology Conference and Exhibition, Noordwijk, The Netherlands, 2012.

9 C. Negin, S. Ali and Q. Xie, Petroleum, 2016, 2, 324-333.

10 H. Shamsijazeyi, C. A. Miller, M. S. Wong, J. M. Tour and R. Verduzco, J. Appl. Polym. Sci., 2014, 131, 40576.

11 A. Karimi, Z. Fakhroueian, A. Bahramian, N. P. Khiabani, J. B. Darabad, R. Azin and S. Arya, Energy Fuels, 2012, 26, 1028-1036.

12 A. Dehghan Monfared, M. H. Ghazanfari, M. Jamialahmadi and A. Helalizadeh, Energy Fuels, 2016, 3947-3961.

13 M. Salehi, S. J. Johnson and J. T. Liang, Langmuir, 2008, 24, 14099-14107.

14 G. J. Hirasaki, C. A. Miller and M. Puerto, SPE J., 2011, 16, 889-907.

15 D. C. Standnes and T. Austad, J. Pet. Sci. Eng., 2000, 28, $123-$ 143.

16 D. Luo, F. Wang, J. Zhu, F. Cao, Y. Liu, X. Li, R. C. Willson, Z. Yang, C.-W. Chu and Z. Ren, Proc. Natl. Acad. Sci. U. S. A., 2016, 201608135.

17 J. Giraldo, P. Benjumea, S. Lopera, F. B. Cortés and M. A. Ruiz, Energy Fuels, 2013, 27, 3659-3665.

18 A. Maghzi, S. Mohammadi, M. H. Ghazanfari, R. Kharrat and M. Masihi, Exp. Therm. Fluid Sci., 2012, 40, 168-176.

19 K. Wang, C. Wang, L. Sun and F. Yi, Presented in part at the Power and energy engineering conference (APPEEC), AsiaPacific, 2010.

20 G. Cheraghian and L. Hendraningrat, Int. Nano Lett., 2016, 6, 129-138.

21 S. Thomas, Oil Gas Sci. Technol., 2008, 63, 9-19.

22 J. Sheng, Modern Chemical Enhanced Oil Recovery: Theory and Practice, Gulf Professional Publishing, 2010.

23 N. Glaser, D. Adams, A. Böker and G. Krausch, Langmuir, 2006, 22, 5227-5229.

24 Z. Cheng, A. F. Mejia, A. Diaz, A. Clearfield, M. S. Mannan and Y. W. Chang, US Pat., No. 9586983, Washington, DC, Patent and Trademark Office, 2017.

25 W. Xiang, S. Zhao, X. Song, S. Fang, F. Wang, C. Zhong and Z. Luo, Phys. Chem. Chem. Phys., 2017, 19, 7576-7586.

26 P. G. de Gennes, Angew. Chem., Int. Ed., 1992, 31, 842-845.

27 A. Walther and A. H. Müller, Chem. Rev., 2013, 113, 51945261.

28 N. A. Ogolo, O. A. Olafuyi and M. O. Onyekonwu, Presented in part at the SPE Saudi Arabia section technical symposium and exhibition, Al-Khobar, Saudi Arabia, 2012.

29 D. T. Wasan and A. D. Nikolov, Nature, 2003, 423, 156.

30 D. Wasan, A. Nikolov and K. Kondiparty, Curr. Opin. Colloid Interface Sci., 2011, 16, 344-349.

31 A. Trokhymchuk, D. Henderson, A. Nikolov and D. T. Wasan, Langmuir, 2001, 17, 4940-4947.

32 H. Zhang, A. Nikolov and D. Wasan, Energy Fuels, 2014, 28, 3002-3009.

33 M. Puerto, G. J. Hirasaki, C. A. Miller and J. R. Barnes, SPE J., 2012, 17(01), 11-19.
34 D. A. Espinoza, F. M. Caldelas, K. P. Johnston, S. L. Bryant and C. Huh, Presented in part at the SPE improved oil recovery symposium, Tulsa, Oklahoma, USA, 2010.

35 T. Sharma, G. S. Kumar, B. H. Chon and J. S. Sangwai, J. Ind. Eng. Chem., 2015, 22, 324-334.

36 T. Zhang, D. Davidson, S. L. Bryant and C. Huh, Presented in part at the SPE improved oil recovery symposium, Tulsa, Oklahoma, USA, 2010.

37 T. Zhang, M. Roberts, S. L. Bryant and C. Huh, Presented in part at the SPE international symposium on oilfield chemistry, Woodlands, Texas, 2009.

38 J. W. Kim, R. J. Larsen and D. A. Weitz, J. Am. Chem. Soc., 2006, 128, 14374-14377.

39 J.-G. Park, J. D. Forster and E. R. Dufresne, J. Am. Chem. Soc., 2010, 132, 5960-5961.

40 J. W. Kim, D. Lee, H. C. Shum and D. A. Weitz, Adv. Mater., 2008, 20, 3239-3243.

41 A. J. Worthen, H. G. Bagaria, Y. Chen, S. L. Bryant, C. Huh and K. P. Johnston, J. Colloid Interface Sci., 2013, 391, 142151.

42 T. Zhang, D. Espinosa, K. Y. Yoon, A. R. Rahmani, H. Yu, F. M. Caldelas, S. Ryoo, M. Roberts, M. Prodanovic, K. P. Johnston, T. E. Milner, S. L. Bryant and C. Huh, Presented in part at the Offshore technology conference, Houston, Texas, USA, 2011.

43 S. S. Adkins, D. Gohil, J. L. Dickson, S. E. Webber and K. P. Johnston, Phys. Chem. Chem. Phys., 2007, 9, 6333-6343.

44 D. A. Espinoza, F. M. Caldelas, K. P. Johnston, S. L. Bryant and C. Huh, Presented in part at the SPE Improved Oil Recovery Symposium, Tulsa, Oklahoma, USA, 2010.

$45 \mathrm{~J}$. Yu, C. An, D. Mo, N. Liu and R. L. Lee, Presented in part at the SPE improved oil recovery symposium, Tulsa, Oklahoma, USA, 2012.

46 F. Guo and S. Aryana, Fuel, 2016, 186, 430-442.

47 T. Skauge, K. Spildo and A. Skauge, Presented in part at the SPE improved oil recovery symposium, Tulsa, Oklahoma, USA, 2010.

48 L. Hendraningrat, S. Li and O. Torsæter, J. Pet. Sci. Eng., 2013, 111, 128-138.

49 J. Gulbis, M. King, G. Hawkins and H. Brannon, SPE Prod. Eng., 1992, 7, 9-14.

50 S. Hatami Boura, M. Samadzadeh, M. Peikari and A. Ashrafi, Presented in part at the SPE International Conference on Oilfield Corrosion, Aberdeen, UK, 2010.

51 K. Kusanagi, S. Murata, Y. Goi, M. Sabi, K. Zinno, Y. Kato, N. Togashi, T. Matsuoka and Y. Liang, Presented in part at the SPE/IATMI Asia pacific oil \& gas conference and exhibition, Nusa Dua, Bali, Indonesia, 2015.

$52 \mathrm{H}$. Hu, Z. Zhao, Y. Gogotsi and J. Qiu, Environ. Sci. Technol. Lett., 2014, 1, 214-220.

53 W. Zhai, G. Li, P. Yu, L. Yang and L. Mao, J. Phys. Chem. C, 2013, 117, 15183-15191.

54 M. Shen and D. E. Resasco, Langmuir, 2009, 25, 1084310851.

55 K. Kusanagi, S. Murata, Y. Goi, M. Sabi, K. Zinno, Y. Kato, N. Togashi, T. Matsuoka and Y. Liang, Presented in part at 
the SPE/IATMI Asia pacific oil \& gas conference and exhibition, Nusa Dua, Bali, Indonesia, 2015.

56 H. Ehtesabi, M. M. Ahadian, V. Taghikhani and M. H. Ghazanfari, Energy Fuels, 2013, 28, 423-430.

57 I. Kalashnikova, H. Bizot, B. Cathala and I. Capron, Langmuir, 2011, 27, 7471-7479.

58 I. Kalashnikova, H. Bizot, P. Bertoncini, B. Cathala and I. Capron, Soft Matter, 2013, 9, 952-959.

59 H.-M. Gao, Z.-Y. Lu, H. Liu, Z.-Y. Sun and L.-J. An, J. Chem. Phys., 2014, 141, 134907.

60 M. A. Creighton, Y. Ohata, J. Miyawaki, A. Bose and R. H. Hurt, Langmuir, 2014, 30, 3687-3696.

61 J. Kim, L. J. Cote, F. Kim, W. Yuan, K. R. Shull and J. Huang, J. Am. Chem. Soc., 2010, 132, 8180-8186.

62 A. F. Mejia, A. Diaz, S. Pullela, Y.-W. Chang, M. Simonetty, C. Carpenter, J. D. Batteas, M. S. Mannan, A. Clearfield and Z. Cheng, Soft Matter, 2012, 8, 10245.

63 Y. Yu and Z. Cheng, Angew. Chem., submitted.

64 X. Wang, L. Zhang, Y.-H. Yu, L. Jia, M. S. Mannan, Y. Chen and Z. Cheng, Sci. Rep., 2015, 5, 13357.

65 S. Guillot, F. Bergaya, C. de Azevedo, F. Warmont and J.-F. Tranchant, J. Colloid Interface Sci., 2009, 333, 563-569.

66 F. Yang, S. Liu, J. Xu, Q. Lan, F. Wei and D. Sun, J. Colloid Interface Sci., 2006, 302, 159-169.

67 E. Rodriguez Pin, M. Roberts, H. Yu, C. Huh and S. L. Bryant, Presented in part at the SPE annual technical conference and exhibition, New Orleans, Louisiana, 2009.

68 M. F. Haase, D. Grigoriev, H. Moehwald, B. Tiersch and D. G. Shchukin, J. Phys. Chem. C, 2010, 114, 17304-17310.

69 S. Sihler, A. Schrade, Z. Cao and U. Ziener, Langmuir, 2015, 31, 10392-10401.

70 D. J. Voorn, W. Ming and A. M. van Herk, Macromolecules, 2006, 39, 2137-2143.

71 S. Abbasi, A. Shahrabadi and H. Golghanddashti, Presented in part at the SPE European formation damage conference, Noordwijk, The Netherlands, 2011.

72 C. Amorim, R. Lopes, R. Barroso, J. Queiroz, D. Alves, C. Perez and H. Schelin, Nucl. Instrum. Methods Phys. Res., Sect. A, 2007, 580, 768-770.

73 R. L. Anderson, I. Ratcliffe, H. C. Greenwell, P. A. Williams, S. Cliffe and P. V. Coveney, Earth-Sci. Rev., 2010, 98, 201216.

74 K. Haraguchi and T. Takehisa, Adv. Mater., 2002, 14, 1120.

75 I. J. Gonzalez and G. W. Scherer, Environ. Geol., 2004, 46, 364-377.

76 B. Singh and I. D. R. Mackinnon, Clays Clay Miner., 1996, 44, 825-834.

77 J. E. F. C. Gardolinski and G. Lagaly, Clay Miner., 2005, 40, 547-556.

78 Y. Kuroda, K. Ito, K. Itabashi and K. Kuroda, Langmuir, 2011, 27, 2028-2035.

79 L. Hendraningrat and L. Shidong, Presented in part at the SPE Russian oil and gas exploration and production technical conference and exhibition, Moscow, Russia, 2012.
80 S. Rege and H. Fogler, AIChE J., 1988, 34, 1761-1772.

81 T. Zhang, PhD dissertation, University of Texas-Austin, 2012.

82 M. Ahmadi, A. Habibi, P. Pourafshari and S. Ayatollahi, Presented in part at the SPE Middle East Oil and Gas Show and Conference, Manama, Bahrain, 2011.

83 A. D. Dinsmore, M. F. Hsu, M. G. Nikolaides, M. Marquez, A. R. Bausch and D. A. Weitz, Science, 2002, 298, 1006-1009.

84 J. W. J. de Folter, E. M. Hutter, S. I. R. Castillo, K. E. Klop, A. P. Philipse and W. K. Kegel, Langmuir, 2014, 30, 955-964.

85 B. Madivala, S. Vandebril, J. Fransaer and J. Vermant, Soft Matter, 2009, 5, 1717-1727.

86 G. J. Hirasaki, Soc. Pet. Eng. J., 1982, 22(6), 971-982.

87 E. Alagic, K. Spildo, A. Skauge and J. Solbakken, J. Pet. Sci. Eng., 2011, 78, 220-227.

88 J. Saien and S. Akbari, J. Chem. Eng. Data, 2006, 51, 18321835.

89 D. Villers and J. K. Platten, J. Phys. Chem., 1988, 92, 40234024.

90 E. C. M. Vermolen, M. J. T. Van Haasterecht, S. K. Masalmeh, M. J. Faber, D. M. Boersma and M. A. Gruenenfelder, Presented in part at the SPE Middle East oil and gas show and conference, Manama, Bahrain, 2011.

91 A. D. Monfared, M. H. Ghazanfari, M. Jamialahmadi and A. Helalizadeh, Chem. Eng. J., 2015, 281, 334-344.

92 B. P. Binks and P. D. I. Fletcher, Langmuir, 2001, 17, 47084710.

93 A. Kumar, B. J. Park, F. Tu and D. Lee, Soft Matter, 2013, 9, 6604-6617.

94 Y. K. Takahara, S. Ikeda, S. Ishino, K. Tachi, K. Ikeue, T. Sakata, T. Hasegawa, H. Mori, M. Matsumura and B. Ohtani, J. Am. Chem. Soc., 2005, 127, 6271-6275.

95 M. A. Fernandez-Rodriguez, Y. Song, M. Á. RodríguezValverde, S. Chen, M. A. Cabrerizo-Vilchez and R. Hidalgo-Alvarez, Langmuir, 2014, 30, 1799-1804.

96 R. Taylor, S. Coulombe, T. Otanicar, P. Phelan, A. Gunawan, W. Lv, G. Rosengarten, R. Prasher and H. Tyagi, J. Appl. Phys., 2013, 113, 19.

97 L. J. Felicia and J. Philip, Langmuir, 2015, 31, 3343-3353.

98 V. Mahendran and J. Philip, Appl. Phys. Lett., 2014, 105, 123110.

99 A. Zaibudeen and J. Philip, Opt. Mater., 2017, 66, 117-121. 100 E. A. Taborda, C. A. Franco, S. H. Lopera, V. Alvarado and F. B. Cortés, Fuel, 2016, 184, 222-232.

101 M. Mehrali, E. Sadeghinezhad, S. T. Latibari, S. N. Kazi, M. Mehrali, M. N. B. Zubir and H. S. C. Metselaar, Nanoscale Res. Lett., 2014, 9, 12.

102 N. Yahya, M. Kashif, N. Nasir, M. Niaz Akhtar and N. M. Yusof, J. Nano Res., 2012, 17, 115-126.

103 N. Kothari, B. Raina, K. B. Chandak, V. Iyer and H. P. Mahajan, SPE EUROPEC/EAGE Annual Conference and Exhibition, Society of Petroleum Engineers, 2010. 